\title{
Interface Dependent Plasmon Induced Enhancement in Dye-Sensitized Solar Cells Using Gold Nanoparticles
}

\author{
Matheus Costa de Oliveira, ${ }^{1}$ André Luis Silveira Fraga, ${ }^{2}$ \\ Anderson Thesing, ${ }^{2}$ Rocelito Lopes de Andrade, ${ }^{2}$ \\ Jacqueline Ferreira Leite Santos, ${ }^{1,2}$ and Marcos José Leite Santos ${ }^{1,2}$ \\ ${ }^{1}$ Laboratório de Materiais Aplicados e Interfaces, Instituto de Química, Universidade Federal do Rio Grande do Sul (UFRGS), \\ 91501-970 Porto Alegre, RS, Brazil \\ ${ }^{2}$ Programa de Pós-Graduação em Ciências de Materiais (PGCIMAT), Universidade Federal do Rio Grande do Sul, \\ 91501-970 Porto Alegre, RS, Brazil
}

Correspondence should be addressed to Marcos José Leite Santos; mjls@ufrgs.br

Received 31 August 2015; Accepted 26 October 2015

Academic Editor: Subrata Kundu

Copyright (c) 2015 Matheus Costa de Oliveira et al. This is an open access article distributed under the Creative Commons Attribution License, which permits unrestricted use, distribution, and reproduction in any medium, provided the original work is properly cited.

\begin{abstract}
We report a study on plasmon-induced photoelectrochemistry from gold nanoparticles incorporated in dye-sensitized solar cells, assembled in two different configurations: $\mathrm{TiO}_{2} / \mathrm{Au}_{\text {nanop }} / \mathrm{Dye}$ and $\mathrm{TiO}_{2} / \mathrm{Dye} / \mathrm{Au}_{\text {nanop }}$. Although the presence of the plasmonic material resulted in enhanced photocurrent and energy conversion efficiency, a decrease of fill factor was observed. Electrical modeling of the solar cells was performed and revealed a simultaneous decrease of parallel resistance and increase of series resistance, related to the presence of gold nanoparticles. The enhancement in photocurrent was related to a combination of strong plasmon-induced electric fields and light scattering, which overcome the loss in electrical properties. In addition, the overall increase in efficiency was found dependent on the interface where the plasmonic material is placed. The highest efficiency obtained from $\mathrm{TiO}_{2} / \mathrm{Au}_{\text {nanop }} /$ Dye was attributed to a larger density of photoexcited electrons allowed to be transferred towards conduction band of $\mathrm{TiO}_{2}$.
\end{abstract}

\section{Introduction}

Great advances in nanofabrication have allowed the study of well-organized nanostructure arrays, such as nanoholes and surface relief gratings, providing better comprehension and description of the plasmon propagation modes [1-8]. Nevertheless, metallic nanoparticles presenting wellcontrolled shape and small size distribution have been attracting increasing attention, due to simple and efficient synthetic approaches, which requires minimum apparatus $[9,10]$. Metallic nanoparticles with diameter smaller than the incident wavelength, present localized surface plasmons resonance, which result from the interaction between the electrons in the nanoparticles and the incident electromagnetic field. Charge separation within the nanoparticle leads to extraordinary optical properties related to improved absorption and light scattering [11]. The plasmon mode is well described by Mie's theory for isolated metallic nanoparticles; however, concerning nanoparticles in a film, the electromagnetic theory developed by Maxwell is more appropriate, once plasmons coupling between adjacent particles should be considered $[12,13]$. In addition to the nature of surface plasmons, their effect on the surrounding media has been intensively studied [14-19]. Metallic nanostructures have been widely applied in photoluminescence [20], Raman spectroscopy [21, $22]$, sensing $[23,24]$, and, more recently, the development of photovoltaic devices with high photoconversion efficiency [25-28]. These applications are based on the modification of the optical density of states that store and/or route the electromagnetic energy in a given medium. 
Pristine $\mathrm{TiO}_{2}$ presents a large band gap, which is a limiting factor for the development of efficient DSSCs. In order to overcome this disadvantage, the semiconductor is sensitized to increase the wavelength range for light absorption. Aiming to improve dye sensitization, charge transfer, and mobility, several $\mathrm{TiO}_{2}$ nanostructures have been studied [29-31]. Concerning efficient sensitization of a $10 \mu \mathrm{m}$ thick mesoporous film composed of $\mathrm{TiO}_{2}$ nanoparticles with ca. $20 \mathrm{~nm}$ in diameter, the effective dye sensitizer layer can be estimated as only ca. $100 \mathrm{~nm}$ thick; therefore, the layer is not thick enough to allow high absorbance of the solar spectrum. One alternative to overcome this issue is by adding a lightscattering layer of $\mathrm{TiO}_{2}$ nanoparticles, which improves light harvesting. However, this scattering layer makes the devices thicker and opaque. Another alternative is the use of plasmonic substrates, such as metallic nanoparticles, nanohole arrays in metal films, and surface relief gratings. These substrates promote light trapping in the photoactive layer, which has resulted in improved absorption and enhanced energy conversion efficiency [23, 32-35]. The contribution of plasmonic materials to the efficiency of solar cells results from a variety of competing effects [36]; for example, as the plasmons are a surface phenomenon, the distance between nanoparticles and surrounding medium strongly affects the interaction between plasmon field and medium. In addition, the propagation of the surface plasmon electromagnetic field, and therefore the damping energy from the oscillator, depends on the surrounding properties [37].

In order to investigate the effect of an external field provided by gold nanoparticles on the efficiency of DSSC, in this work we have studied two different configurations of the DSSC: (i) gold nanoparticles placed between the semiconductor and the sensitizer $\left(\mathrm{TiO}_{2} / \mathrm{Au}_{\text {nanop }} /\right.$ Dye $)$ and (ii) gold nanoparticles placed on top of the sensitized semiconductor $\left(\mathrm{TiO}_{2} /\right.$ Dye/ $\left.\mathrm{Au}_{\text {nanop }}\right)$.

\section{Materials and Methods}

2.1. Materials. Titanium (IV) isopropoxide 97\%, gold (III) chloride hydrate, and hexachloroplatinic acid were purchased from Aldrich. Ethanol and $\mathrm{HCl} 37 \%$ were purchased from Merck. cis-Diisothiocyanato-bis $\left(2,2^{\prime}\right.$-bipyridyl- $4,4^{\prime}$ dicarboxylic acid) ruthenium(II), Meltonix, and fluorinedoped tin oxide (FTO, $15 \Omega / \mathrm{sq}$ ) glass were purchased from Solaronix.

2.2. Synthesis of Gold Nanoparticles and Deposition of Gold Nanoparticle Film. Gold colloidal nanoparticles were prepared according to previous methods reported in the literature [38]. $1 \mathrm{mmol} \cdot \mathrm{L}^{-1} \mathrm{HAuCl}_{4} \cdot 3 \mathrm{H}_{2} \mathrm{O}$ aqueous solution $(100 \mathrm{~mL})$ was refluxed at $120^{\circ} \mathrm{C}$ under vigorous stirring. Next, $2.5 \mathrm{~mL}$ of sodium citrate solution $\left(10 \mathrm{mmol} \cdot \mathrm{L}^{-1}\right)$ was quickly added to the reaction vessel. Ultrapure water was used throughout the experiments. The gold nanoparticles film was obtained by drop-casting $10 \mu \mathrm{L}$ of concentrated gold nanoparticles solution on the substrates followed by drying at $50^{\circ} \mathrm{C}$.

2.3. Synthesis of $\mathrm{TiO}_{2}$ and Paste Preparation. The approach used to obtain $\mathrm{TiO}_{2}$ nanoparticles is based on Graetzel work [39]: $5.7 \mathrm{~mL}$ of acetic acid was added quickly to $15 \mathrm{~mL}$ of titanium isopropoxide under stirring at room temperature for $15 \mathrm{~min}$. After that the modified precursor was quickly added to $72.5 \mathrm{~mL}$ of deionized water under vigorous stirring and a white precipitate was formed. This mixture was kept under constant stirring for one hour at room temperature to complete the hydrolysis reaction. At this point, $1.0 \mathrm{~mL}$ of nitric acid $63 \%$ was added, with stirring for 8 hours at $80^{\circ} \mathrm{C}$. Lastly, $95 \mathrm{~mL}$ of water was added to the mixture to be autoclaved and heat at $230^{\circ} \mathrm{C}$ for 12 hours. Finally, all samples were rinsed with anhydrous ethanol. The samples were calcinated at $450^{\circ} \mathrm{C}$ during 30 minutes, in order to obtain the anatase phase of $\mathrm{TiO}_{2}$.

2.4. Optical and Morphological Characterization. The absorption spectra from the mesoporous $\mathrm{TiO}_{2}$ film, dye-sensitized $\mathrm{TiO}_{2}\left(\mathrm{TiO}_{2} / \mathrm{Dye}\right)$, gold nanoparticles solution, gold nanoparticles film (AuNP film), gold nanoparticles adsorbed between $\mathrm{TiO}_{2}$ and dye $\left(\mathrm{TiO}_{2} / \mathrm{Au}_{\text {nanop }} / \mathrm{Dye}\right)$, and gold nanoparticles placed on the dye-sensitized $\mathrm{TiO}_{2}\left(\mathrm{TiO}_{2} / \mathrm{Dye} / \mathrm{Au}_{\text {nanop }}\right)$ were obtained in a Shimadzu UV-2450PC spectrophotometer. The spectra of the scattering films were obtained by reflectance mode. The morphological characterizations of $\mathrm{TiO}_{2}$ and gold nanoparticles were obtained by transmission electron microscopy (TEM) Libra Zeiss 120 and Scanning Electron Microscopy (SEM) Philips CM300.

2.5. Dye-Sensitized Solar Cells Assembly. The procedure to obtain the $\mathrm{TiO}_{2}$ paste can be found elsewhere [40]. The paste was screen-printed on a transparent conductive substrate (FTO), previously immersed in $40 \mathrm{mmol} \cdot \mathrm{L}^{-1} \mathrm{TiCl}_{4}$ aqueous solution at $80^{\circ} \mathrm{C}$ for 30 minutes. Next, the substrate was heated on a hot plate at $125^{\circ} \mathrm{C}$ for 20 minutes, followed by heating to $500^{\circ} \mathrm{C}$ for sintering. After cooling down to $40^{\circ} \mathrm{C}$, the substrates were immersed in the sensitizer solution. The counter electrodes were prepared by coating the FTO surface with $1 \mathrm{mmol} \cdot \mathrm{L}^{-1}$ of hexachloroplatinic acid solution $(30 \mu \mathrm{L})$ and heating at $500^{\circ} \mathrm{C}$. The mediator, responsible for the regeneration of the dye, was placed between the dyesensitized photoanode and the counterelectrode. The solar cell was sealed by using a polymeric film of low melting temperature (Meltonix). For the devices containing gold nanoparticles, two different solar cells configurations were assembled where $10 \mu \mathrm{L}$ of $20 \%$ of gold nanoparticles (w/w) dispersion was drop-casted (i) on top of the $\mathrm{TiO}_{2}$ mesoporous film $\left(\mathrm{TiO}_{2} / \mathrm{Au}_{\text {nanop }} / \mathrm{Dye}\right)$ and (ii) on top of the dye-sensitized $\mathrm{TiO}_{2}\left(\mathrm{TiO}_{2} / \mathrm{Dye} / \mathrm{Au}_{\text {nanop }}\right)$ as shown in Figure 1.

2.6. Characterization of the Solar Cells. Current density versus voltage curves was performed using a Keithley 2400 source measure unit. A Xenon lamp $(300 \mathrm{~W})$ with an AM 1.5 filter was used and the light intensity corresponding to $100 \mathrm{~mW} \cdot \mathrm{cm}^{-2}$ (1 sun) was calibrated with an optical power meter (Newport). Incident photon-to-current efficiency (IPCE) measurements were performed using the same apparatus, in addition to a cornerstone monochromator. 

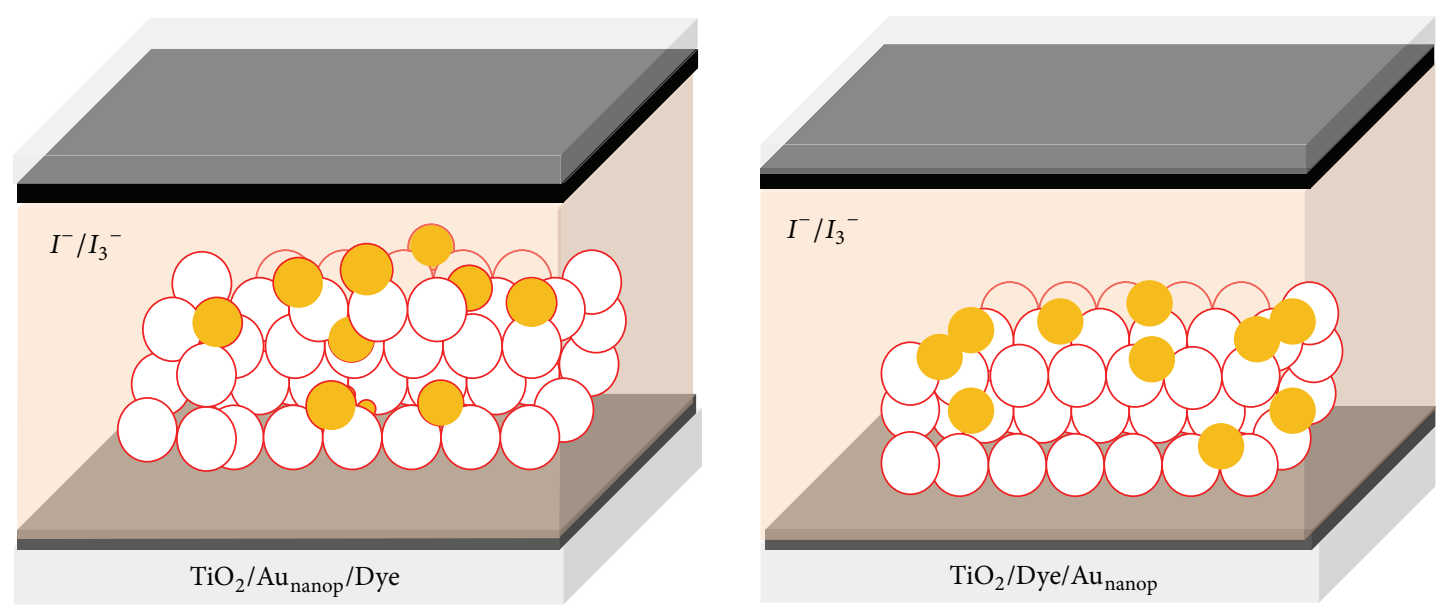

FIgURE 1: Schematic illustration showing the architecture of the devices: gold nanoparticles placed on top of the $\mathrm{TiO}_{2}$ mesoporous film $\left(\mathrm{TiO}_{2} / \mathrm{Au}_{\text {nanop }} / \mathrm{Dye}\right)$ and gold nanoparticles placed on top of the dye-sensitized $\mathrm{TiO}_{2}$ film $\left(\mathrm{TiO}_{2} / \mathrm{Dye} / \mathrm{Au}_{\text {nanop }}\right)$.

\section{Results and Discussions}

Figure 2 shows the TEM images of $\mathrm{TiO}_{2}$ nanoparticles and gold nanoparticles presenting ca. 18 and $19 \mathrm{~nm}$ in diameter, respectively. Gold nanoparticles with this diameter present plasmon mode within the visible range, overlapping the absorption spectrum of the sensitizer (N3). In addition, according to McFarland and Tang [41], photoexcited electrons with energies of $\sim 1 \mathrm{eV}$ above the gold Fermi level have $20-150 \mathrm{~nm}$ free path in $\mathrm{Au}$ and other metals with low-lying or filled $\mathrm{d}$ bands. Therefore, in the assembling $\mathrm{TiO}_{2} / \mathrm{Au}_{\text {nanop }} /$ Dye, the photoexcited electrons in the dye should be able to pass through the gold nanoparticles towards $\mathrm{TiO}_{2}$ conduction band.

Figure 3 shows the normalized absorption spectra of $\mathrm{N} 3$ in solution, mesoporous $\mathrm{TiO}_{2}$ film, gold nanoparticles solution and gold nanoparticles deposited on a glass slide as a film. One can observe that $\mathrm{TiO}_{2}$ presents absorption mode within the ultraviolet region, with band gap edge at ca. $400 \mathrm{~nm}$. The gold nanoparticles in solution present extinction wavelength maximum at $c a .490 \mathrm{~nm}$, corresponding to spherical shaped gold nanoparticles with average diameter of $20 \mathrm{~nm}$ as shown in the TEM images (Figure 2) [42]. Au nanoparticles in a film present plasmon mode shifted to lower energies when compared to Au nanoparticles in solution. This behavior is related to the coupling of the plasmon modes from nearby particles $[43,44]$. In the film, photons with lower energy will match the electrons oscillation frequency within nanoparticle agglomerates. According to the literature, absorptions at lower energies (ca. $350 \mathrm{~nm}$ ) are associated with interband transitions [45]. The sensitizer N3 presents broad absorption range with maximum at 400 and $530 \mathrm{~nm}$, hence absorbing light from the UV region to nearly the entire visible spectrum. One can observe an overlap between the absorption spectra of the sensitizer and the extinction modes of the gold nanoparticles.

In addition to the particle nature, size and geometry, the dielectric function of the surrounding media also affects the extinction spectra of plasmonic nanoparticles, once it affects the energy damping from the oscillator and the strength of the dipole created within the particle. In order to confirm whether the dye can be adsorbed on the gold nanoparticles, the plasmon energy was monitored before and after dipping a gold nanoparticles film in N3 solution (Figure 3(b)). One can observe a ca. $4 \mathrm{~nm}$ red shift indicating changes in local surface-refractive index of gold nanoparticles, due to a chemical adsorption, expected from molecules containing sulfur in the chemical structure [23, 46, 47].

Small size gold nanoparticles present discrete energy levels and a larger shift in the Fermi levels is expected for a small electron accumulation $[48,49]$. On the other hand, nanoparticle agglomerates behave like large particles and more electron accumulation is required to achieve the same upward shift of the Fermi level. According to the literature, electrons in nanoparticle agglomerates can recombine with the oxidized $\mathrm{N} 3$ molecules or with the $\mathrm{I}^{-} / \mathrm{I}_{3}{ }^{-}$redox electrolyte before they can be transferred to the conduction band of $\mathrm{TiO}_{2}$, resulting in a poor photocurrent [50]. Hence, there is an ideal concentration of plasmonic material which will allow improved absorbance and photocurrent [51]. To avoid interference of concentration on the performance of the DSSC, the same amount of gold nanoparticles was used in both devices. In the $\mathrm{TiO}_{2} / \mathrm{Dye} / \mathrm{Au}_{\text {nanop }}$ configuration, the sensitizer $\mathrm{N} 3$ presents carboxylic acid groups that efficiently bind to $\mathrm{Ti}^{4+}$ and, as suggested in Figure 3(b), the dye molecules can bind to the gold nanoparticles. In the $\mathrm{TiO}_{2} / \mathrm{Au}_{\text {nanop }} / \mathrm{Dye}$ configuration, gold nanoparticles can be anchored directly on $\mathrm{TiO}_{2}$ by free carboxylate groups of citrates used to stabilize the particles. An efficient bind may occur with empty orbitals of $\mathrm{Ti}^{4+}$, as result of a Lewis acid-base reaction.

Figure 4 shows the absorption spectra of $\mathrm{TiO}_{2} /$ Dye, $\mathrm{TiO}_{2} /$ Dye/Au $\mathrm{An}_{\text {nanop }}$, and $\mathrm{TiO}_{2} / \mathrm{Au}_{\text {nanop }} /$ Dye. One can observe that higher absorbance is achieved when gold nanoparticles are present. This behavior is associated with the 5-order higher cross-section of gold nanoparticles compared to conventional absorbing dyes [42]. For nanoparticles of ca. $40 \mathrm{~nm}$, 

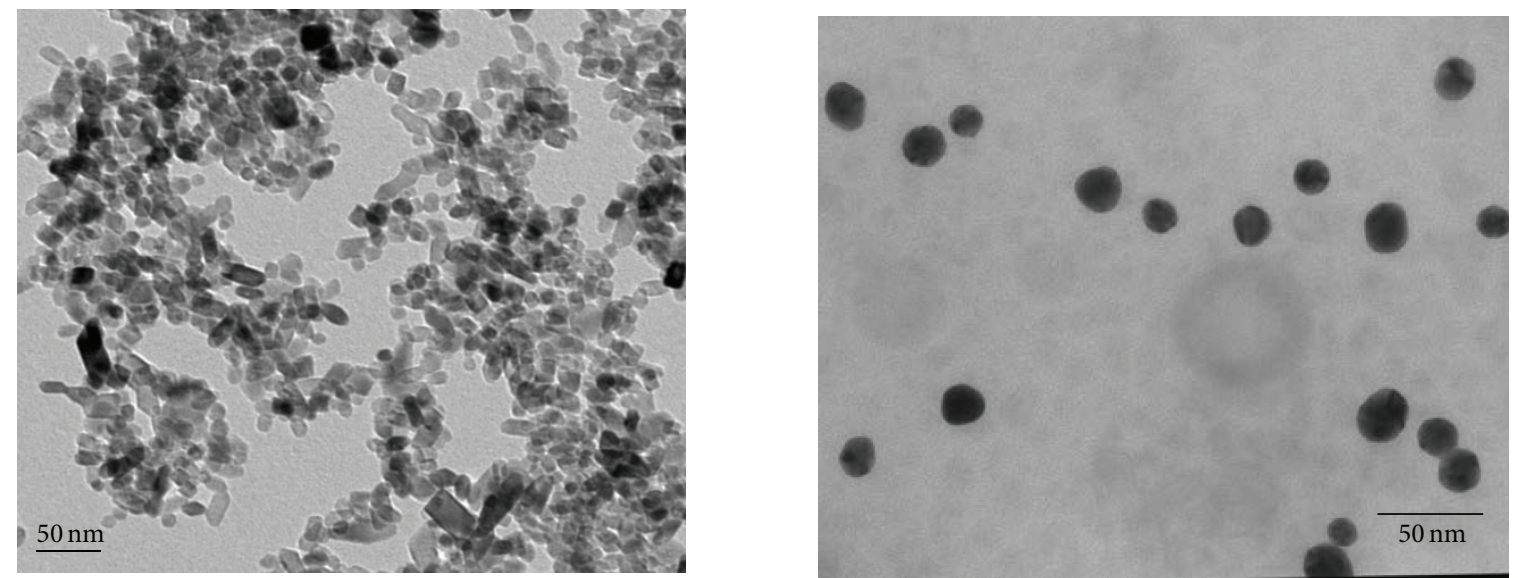

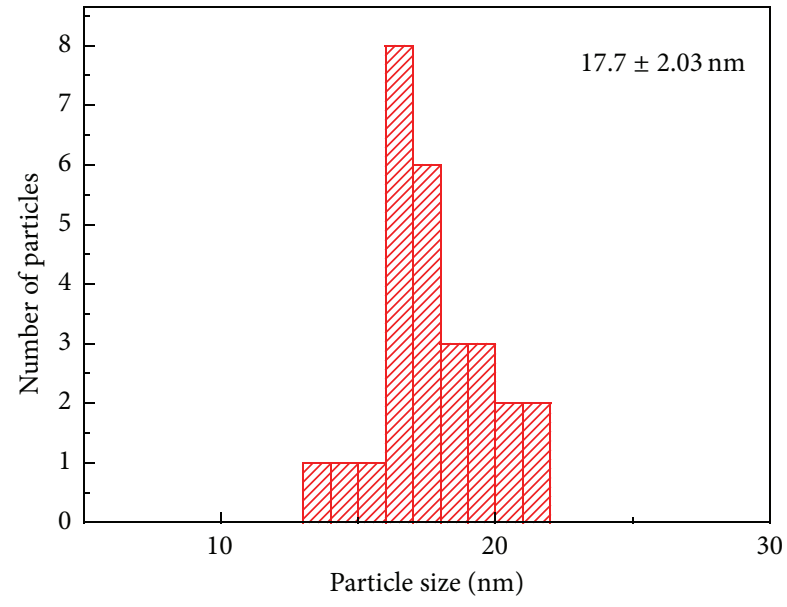

III $\mathrm{TiO}_{2}$

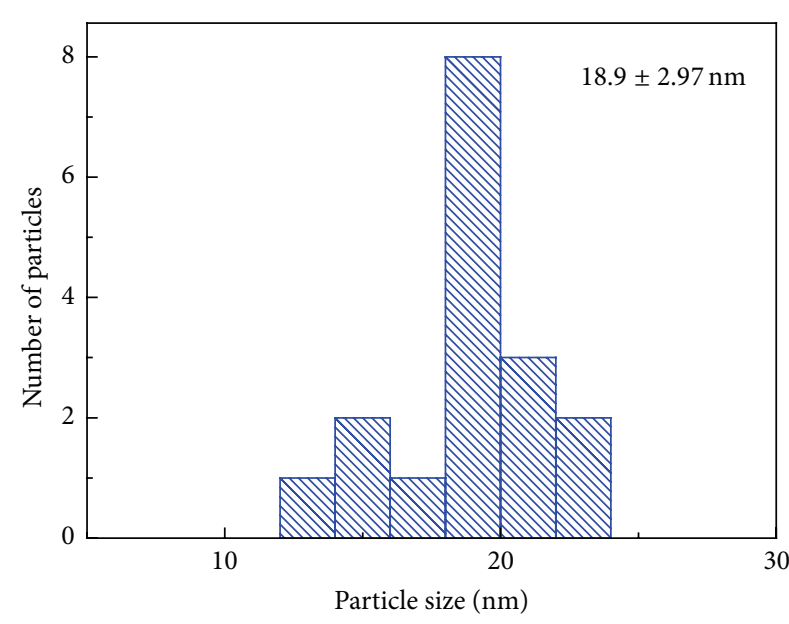

WW AuNP

(a)

(b)

FIGURE 2: TEM images of (a) $\mathrm{TiO}_{2}$ nanoparticles and (b) gold nanoparticles.

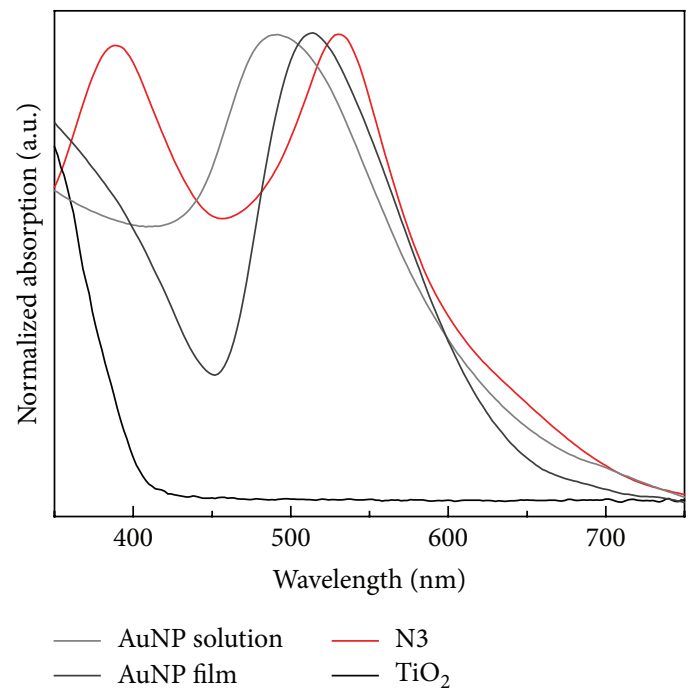

(a)

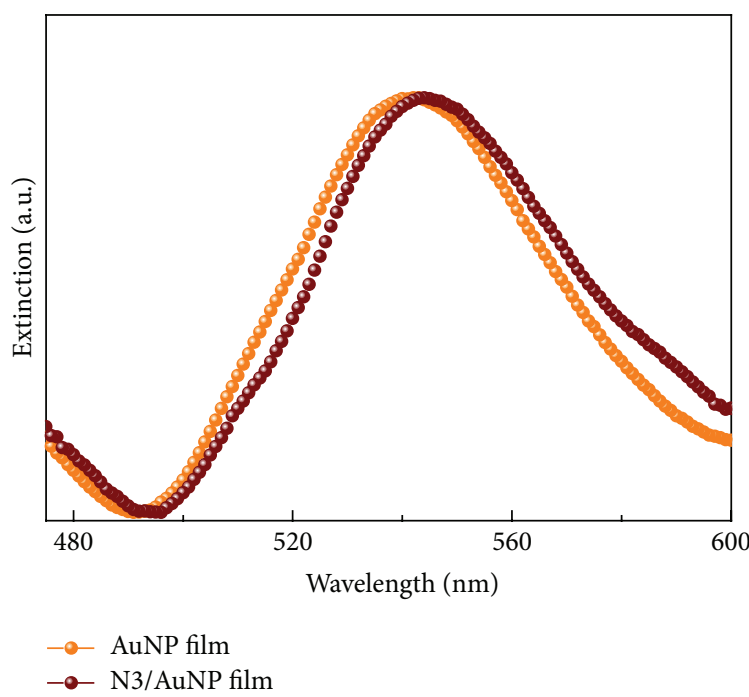

(b)

FIGURE 3: (a) Absorption spectra of N3, mesoporous film of $\mathrm{TiO}_{2}$, gold nanoparticles in solution, and gold nanoparticles deposited on a substrate. (b) Normalized extinction spectra of gold nanoparticles and N3 adsorbed on gold nanoparticles. 


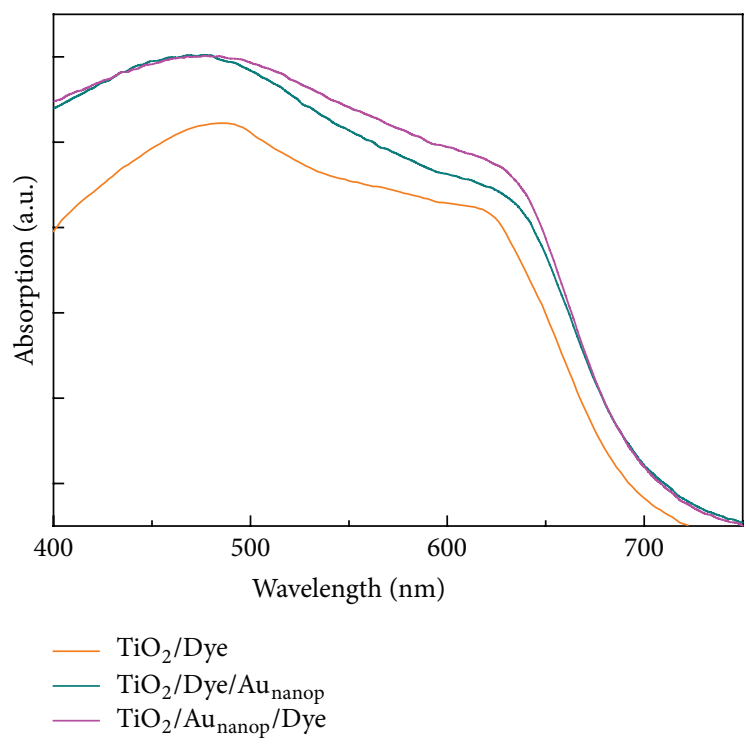

FIgure 4: Absorption spectra of $\mathrm{TiO}_{2} / \mathrm{Dye}, \mathrm{TiO}_{2} / \mathrm{Dye} / \mathrm{Au}_{\text {nanop }}$, and $\mathrm{TiO}_{2} / \mathrm{Au}_{\text {nanop }} /$ Dye.

the absorption cross-section has been earlier calculated as $2.93 \times 10^{-15} \mathrm{~m}^{2}$ and the molar absorption coefficient was ca. $7.66 \times 10^{9} \mathrm{M}^{-1} \mathrm{~cm}^{-1}$. Meanwhile, the N3 sensitizer extinction coefficient was $1.41 \times 10^{4} \mathrm{M}^{-1} \mathrm{~cm}^{-1}$ and $1.45 \times 10^{4} \mathrm{M}^{-1} \mathrm{~cm}^{-1}$ at 400 and $535 \mathrm{~nm}$, respectively [52]. Concerning the two different configurations studied, $\mathrm{TiO}_{2} / \mathrm{Au}_{\text {nanop }} /$ Dye presented higher absorbance within the range between 500 and $650 \mathrm{~nm}$.

In order to study the effect of the plasmonic materials on the performance of the solar cells, three different devices were assembled: (i) a standard device without plasmonic material $\left(\mathrm{TiO}_{2} / \mathrm{Dye}\right.$ ); (ii) $\mathrm{TiO}_{2} / \mathrm{Au}_{\text {nanop }} /$ Dye; and (iii) $\mathrm{TiO}_{2} / \mathrm{Dye} / \mathrm{Au}_{\text {nanop }}$. Figure 5(a) shows the current versus potential curves obtained by illumination through the anode. The results clearly show an improvement in photocurrent allowed by the presence of gold nanoparticles [32-35]. The performance of the assembled devices was evaluated by the following parameters: short-circuit current $\left(I_{\mathrm{sc}}\right)$, open-circuit voltage $\left(V_{\mathrm{oc}}\right)$, fill factor $(\mathrm{FF})$, and efficiency $(\eta)$ (Table 1$)$. In addition to enhanced photocurrent, a $30 \%$ improvement in efficiency was observed for the device assembled with gold nanoparticles deposited directly over $\mathrm{TiO}_{2}$ layer $\left(\mathrm{TiO}_{2} / \mathrm{Au}_{\text {nanop }} /\right.$ Dye $)$.

A slight shift of the open-circuit potential under polychromatic illumination was observed, induced by the plasmonic excitation of the nanoparticles [53]. $V_{\text {oc }}$ is determined by the difference between the chemical potential of the electrolyte and the conductive band of $\mathrm{TiO}_{2}$, which is dependent on the external electrical field, such as the one from the plasmon fields [54]. The presence of the surface plasmon modes provides a strong external electric field, enhancing the open-circuit voltage of the solar cell (Table 1).

In order to further evaluate the contribution of the nanoparticles to the solar cells, a theoretical simulation
TABLE 1: Electrical parameters and the efficiency of the assembled devices.

\begin{tabular}{lcccc}
\hline & $I_{\text {sc }}(\mathrm{mA})$ & $V_{\text {oc }}(\mathrm{V})$ & $\mathrm{FF}(\%)$ & $\eta(\%)$ \\
\hline $\mathrm{TiO}_{2} /$ Dye & 7.3 & 0.68 & 52 & 2.6 \\
$\mathrm{TiO}_{2} / \mathrm{Au}_{\text {nanop }} / \mathrm{Dye}$ & 11.9 & 0.71 & 50 & 4.3 \\
$\mathrm{TiO}_{2} / \mathrm{Dye} / \mathrm{Au}_{\text {nanop }}$ & 9.8 & 0.73 & 48 & 3.4 \\
\hline
\end{tabular}

TABLE 2: $R_{s}$ and $R_{\mathrm{sh}}$ obtained from data presented in Figure 5(b).

\begin{tabular}{lcc}
\hline & $R_{s}[\Omega]$ & $R_{\text {sh }}[\Omega]$ \\
\hline $\mathrm{TiO}_{2} /$ Dye & 11.7 & 671 \\
$\mathrm{TiO}_{2} /$ Dye/Au & 21.2 & 649 \\
$\mathrm{TiO}_{2} / \mathrm{Au}_{\text {nanop }} /$ Dye & 14.8 & 261 \\
\hline
\end{tabular}

was carried out through an electrical modeling using (1), considering the temperature at $22^{\circ} \mathrm{C}$ and $n=2$ :

$$
I=I_{L}-I_{s} \cdot e^{\left[\left(V+I \cdot R_{s}\right) /\left(n \cdot V_{t}\right)\right]}-\frac{\left(V+I \cdot R_{s}\right)}{R_{\mathrm{sh}}},
$$

where $I$ is the current output and $I_{L}$ is the photocurrent, $R_{\text {sh }}$ is the shunt resistance, and $R_{s}$ is the series resistance. Using MATLAB to solve (1), from the experimental data and derivation of potential versus current at $V_{\mathrm{oc}}$ and $I_{\mathrm{sc}}$, the $R_{\mathrm{s}}$ and $R_{\mathrm{sh}}$ values of all devices were determined (Table 2).

The simulated curves presented in Figure 5(b) show good fitting with the experimental data. Although $\mathrm{TiO}_{2} / \mathrm{Au}_{\text {nanop }} /$ Dye presents a much higher photocurrent, it also presents larger series resistance and much lower shunt resistance than $\mathrm{TiO}_{2} /$ Dye, while $\mathrm{TiO}_{2} / \mathrm{Dye} / \mathrm{Au}_{\text {nanop }}$ presents a much higher series resistance and a slightly lower shunt resistance.

IPCE measurements (Figure 6) show that the wavelength-dependent photocurrent response for all devices is consistent with the absorption spectrum of the sensitizer. In addition, both devices containing plasmonic material $\left(\mathrm{TiO}_{2} / \mathrm{Au}_{\text {nanop }} /\right.$ Dye and $\mathrm{TiO}_{2} /$ Dye/ $\left./ \mathrm{Au}_{\text {nanop }}\right)$ present higher conversion efficiency than the standard device $\left(\mathrm{TiO}_{2} / \mathrm{Dye}\right)$. According to the literature, this enhancement in efficiency can be related to a sum of three effects: (i) increased dye excitation due to near-field effects around the nanoparticles: (ii) light scattering the plasmon-induced excited hot electrons on their transfer to the conduction band of $\mathrm{TiO}_{2}[55,56]$.

For both $\mathrm{TiO}_{2} / \mathrm{Au}_{\text {nanop }} /$ Dye and $\mathrm{TiO}_{2} /$ Dye/ $/ \mathrm{Au}_{\text {nanop }}$, light scattering will result in a longer path length, increasing the probability for light absorption. In addition, previous studies have shown that gold nanoparticles absorb light and the energy is then available for dye molecules in an evanescent near field. In the presence of strongly absorbing dyes, such as the N3 studied in this work, the energy from the localized plasmons is transferred to the sensitizer molecules [57].

As the plasmon mode corresponds to discrete states of possible coupling between the incident light and the oscillation of the electronic density within the nanoparticles, the energy of the photon is shared by many electrons; therefore, one should not expect the electrons to have 


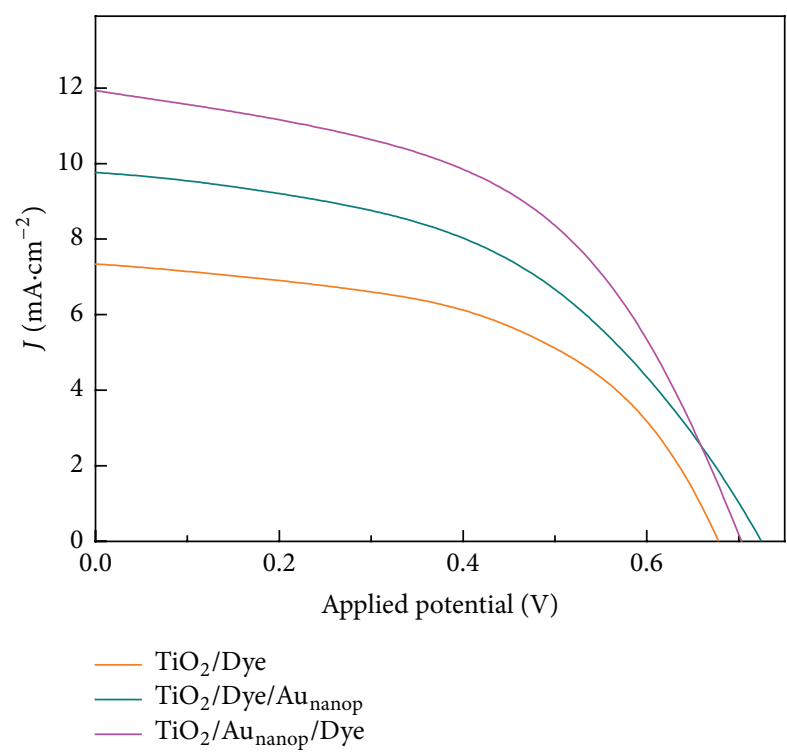

(a)

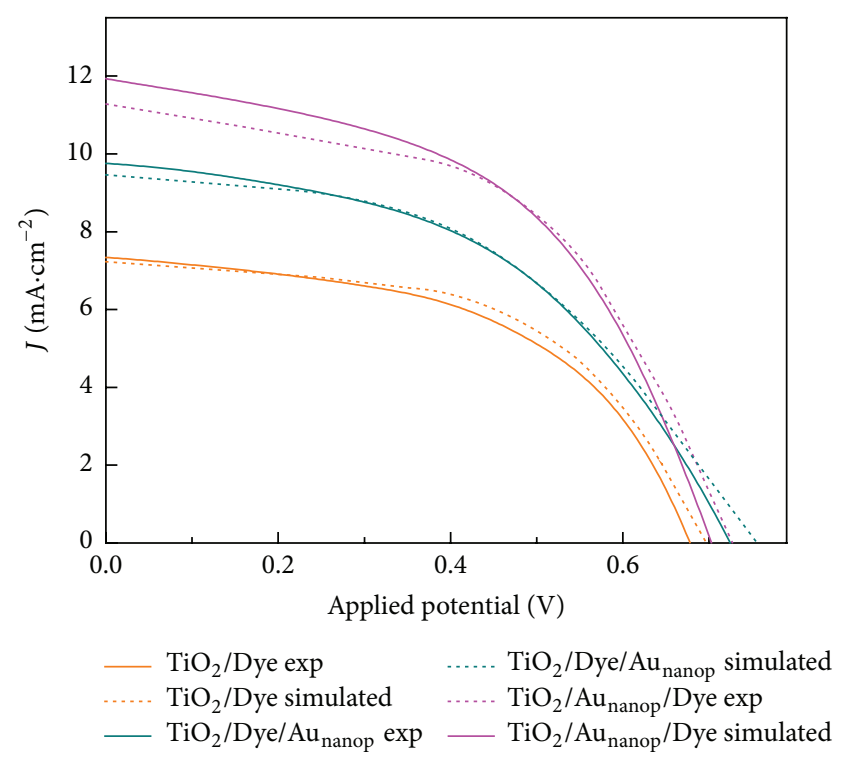

(b)

FIGURE 5: Current versus potential for (a) gold nanoparticles deposited after sensitizing the $\mathrm{TiO}_{2}\left(\mathrm{TiO}_{2} / \mathrm{Dye}_{\mathrm{Au}}\right.$ nanop $)$, before sensitization $\left(\mathrm{TiO}_{2} / \mathrm{Au}_{\text {nanop }} / \mathrm{Dye}\right)$, and for the standard DSSC $\left(\mathrm{TiO}_{2} / \mathrm{Dye}\right)$. (b) Comparison between the experimental and simulated data from electrical modeling.

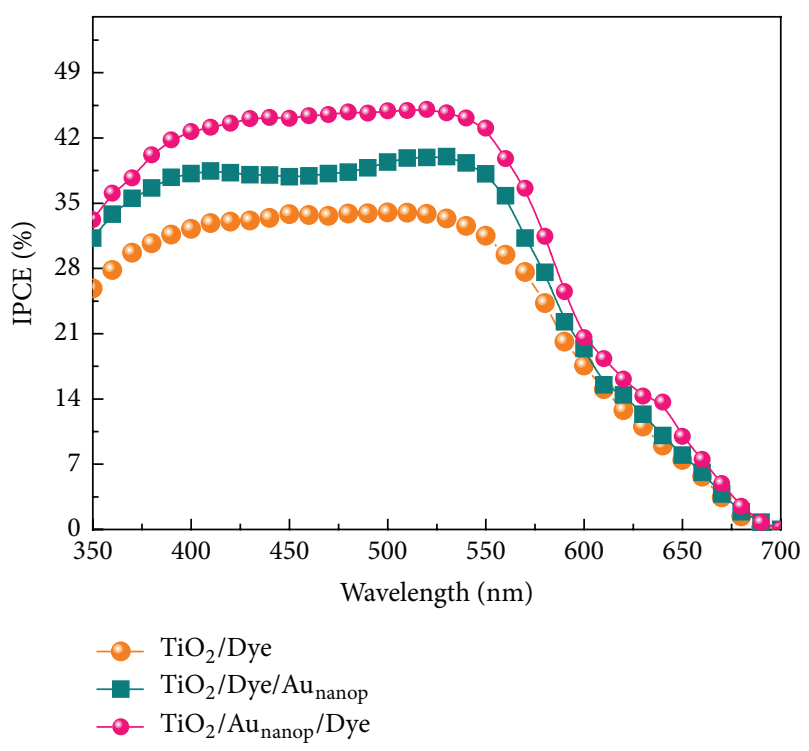

Figure 6: IPCE of $\mathrm{TiO}_{2} /$ Dye, $\mathrm{TiO}_{2} / \mathrm{Au}_{\text {nanop }} /$ Dye, and $\mathrm{TiO}_{2} /$ Dye/ $\mathrm{Au}_{\text {nanop }}$.

sufficient energy to get over a $1.0 \mathrm{eV}$ Schottky barrier at the interface between gold and $\mathrm{TiO}_{2}$ [41]. However, experimental and theoretical studies describe an ultrafast (<240 fs) [58] mechanism involving the plasmon-induced electron transfer from metallic nanostructure to $\mathrm{TiO}_{2}$ nanoparticles $[55,59$, 60]. Figure 7 shows a schematic illustration of the Schottky junction between gold and $\mathrm{TiO}_{2}$ nanoparticles for the assembled devices. A band bending creates an energy barrier, which allows an electron photoexcited in the gold nanoparticle to

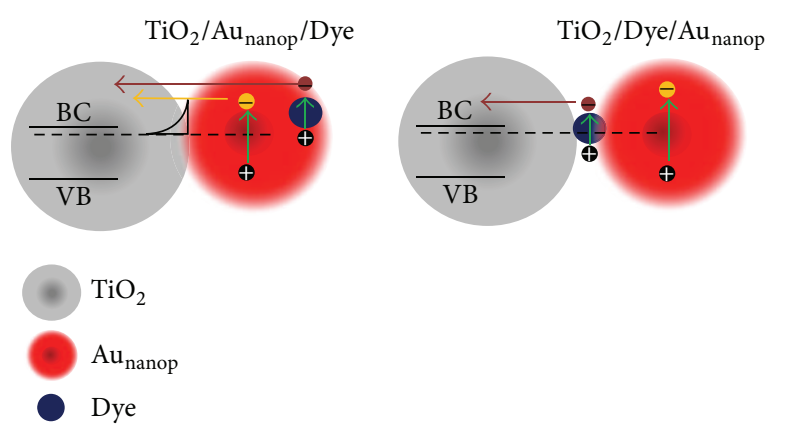

FIGURE 7: Schematic illustration of the plasmonic excitation mechanisms taking place within the assembled devices.

be transferred to the conduction band of the $\mathrm{TiO}_{2}$ [41]. In addition, earlier reports on transient spectroscopy analysis evidences a simultaneous process where photoexcited electrons are injected into $\mathrm{TiO}_{2}$ bulk; meanwhile electrons from a donor in the electrolyte are injected into the oxidized gold nanoparticles $[43,58]$. Concerning the free path of the photoexcited electrons in Au nanoparticles with diameter used in this work, a significant amount of the electrons generated in the dye and injected through the gold nanoparticle will reach the Schottky barrier [56]. Therefore, concerning the two configurations for plasmon enhanced DSSCs, one can assume that, in the $\mathrm{TiO}_{2} / \mathrm{Au}_{\text {nanop }} /$ Dye, the photoexcited electrons in the dye can be injected directly into the conduction band of $\mathrm{TiO}_{2}$. In addition, hot electrons can be transferred from the gold nanoparticles to $\mathrm{TiO}_{2}$ conduction band, improving photocurrent. On the other hand, for the $\mathrm{TiO}_{2} / \mathrm{Dye} / \mathrm{Au}_{\text {nanop' }}$, we suggest two effects to explain the lower photocurrent 
improvement: (i) a smaller amount of dye molecules is affected by the near-field plasmon modes and (ii) a smaller fraction of photoexcited electrons in the gold nanoparticle can be transferred to $\mathrm{TiO}_{2}$, due to the additional potential layer created by the dye molecules.

\section{Conclusion}

The interface where the gold nanoparticles are placed in the assembled device affects the plasmon contribution to the overall energy conversion efficiency. The plasmonic material improves the efficiency of DSSC by increasing light scattering (increasing the light trapping by near-field effects) and transference of hot electrons (increasing the electrons density that reaches the Schottky barrier). These contributions are strongly dependent on the DSSC configuration, once the interface $\mathrm{Au}_{\text {nanop }} / \mathrm{TiO}_{2}$ is more appropriate for injecting photoexcited and hot electrons into $\mathrm{TiO}_{2}$ conduction band. Further studies on these systems are warranted to provide important information about the plasmon energy either to excite electrons in the photoactive layer or to generate hot electrons within the nanoparticles.

\section{Conflict of Interests}

The authors declare that there is no conflict of interests regarding the publication of this paper.

\section{Acknowledgments}

CNPq supported this work. The students thank CAPES for the scholarship. The authors would like to thank also the Centre of Electron Microscopy-CME/UFRGS and CNANO/UFRGS.

\section{References}

[1] W. L. Barnes, A. Dereux, and T. W. Ebbesen, "Surface plasmon subwavelength optics," Nature, vol. 424, no. 6950, pp. 824-830, 2003.

[2] C. Genet and T. W. Ebbesen, "Light in tiny holes," Nature, vol. 445, no. 7123, pp. 39-46, 2007.

[3] A. F. Coskun, A. E. Cetin, B. C. Galarreta, D. A. Alvarez, H. Altug, and A. Ozcan, "Lensfree optofluidic plasmonic sensor for real-time and label-free monitoring of molecular binding events over a wide field-of-view," Scientific Reports, vol. 4, no. 6789, pp. $1-7,2013$.

[4] C. Escobedo, Y.-W. Chou, M. Rahman et al., "Quantification of ovarian cancer markers with integrated microfluidic concentration gradient and imaging nanohole surface plasmon resonance," Analyst, vol. 138, no. 5, pp. 1450-1458, 2013.

[5] R. G. Sabat, N. Rochon, and P. Rochon, "Dependence of surface plasmon polarization conversion on the grating pitch," Journal of the Optical Society of America A: Optics and Image Science, and Vision, vol. 27, no. 3, pp. 518-522, 2010.

[6] H. Wang, W. Zhou, and E. P. Li, "Focused ion beam assisted interface detection for fabricating functional plasmonic nanostructures," Journal of Nanomaterials, vol. 2015, Article ID 468069, 9 pages, 2015.
[7] T. Wu, Y. Liu, Z. Yu, Y. Peng, C. Shu, and H. He, "The sensing characteristics of plasmonic waveguide with a single defect," Optics Communications, vol. 323, pp. 44-48, 2014.

[8] J. W. de Menezes, A. Thesing, C. Valsecchi, L. E. G. Armas, and A. G. Brolo, "Improving the performance of gold nanohole array biosensors by controlling the optical collimation conditions," Applied Optics, vol. 54, no. 21, pp. 6502-6507, 2015.

[9] U. Kreibig and M. Vollmer, Optical Properties of Metal Clusters, vol. 25 of Springer Series in Materials Science, Springer, Berlin, Germany, 1995.

[10] C. F. Bohren and D. R. Huffman, Absorption and Scattering of Light by Small Particles, Wiley-VCH, Weinheim, Germany, 1998.

[11] E. Prodan, C. Radloff, N. J. Halas, and P. Nordlander, "A hybridization model for the plasmon response of complex nanostructures," Science, vol. 302, no. 5644, pp. 419-422, 2003.

[12] S. Bakhti, N. Destouches, and A. V. Tishchenko, "Coupled mode modeling to interpret hybrid modes and fano resonances in plasmonic systems," ACS Photonics, vol. 2, no. 2, pp. 246-255, 2015.

[13] R. D. Near, S. C. Hayden, R. E. Hunter, D. Thackston, and M. A. El-Sayed, "Rapid and efficient prediction of optical extinction coefficients for gold nanospheres and gold nanorods," Journal of Physical Chemistry C, vol. 117, no. 45, pp. 23950-23955, 2013.

[14] G. Zhao, H. Kozuka, and T. Yoko, "Effects of the incorporation of silver and gold nanoparticles on the photoanodic properties of rose bengal sensitized $\mathrm{TiO}_{2}$ film electrodes prepared by solgel method," Solar Energy Materials and Solar Cells, vol. 46, no. 3, pp. 219-231, 1997.

[15] T.-M. Chien, P. Pavaskar, W. H. Hung, S. Cronin, S.-H. Chiu, and S.-N. Lai, "Study of the plasmon energy transfer processes in dye sensitized solar cells," Journal of Nanomaterials, vol. 2015, Article ID 139243, 6 pages, 2015.

[16] X. Ma, X. Li, N. Lun, and S. Wen, "Synthesis of gold nanocatalysts supported on carbon nanotubes by using electroless plating technique," Materials Chemistry and Physics, vol. 97, no. 2-3, pp. 351-356, 2006.

[17] J.-H. Chen, J.-N. Lin, Y.-M. Kang, W.-Y. Yu, C.-N. Kuo, and B.-Z. Wan, "Preparation of nano-gold in zeolites for CO oxidation: Effects of structures and number of ion exchange sites of zeolites," Applied Catalysis A: General, vol. 291, no. 1-2, pp. 162169, 2005.

[18] D. B. Akolekar and S. K. Bhargava, "Investigations on gold nanoparticles in mesoporous and microporous materials," Journal of Molecular Catalysis A: Chemical, vol. 236, no. 1-2, pp. 7786, 2005.

[19] M. Berginc, U. O. Krašovec, and M. Topič, "Solution processed silver nanoparticles in dye-sensitized solar cells," Journal of Nanomaterials, vol. 2014, Article ID 357979, 11 pages, 2014.

[20] J. R. Lakowicz, "Radiative decay engineering 5: metal-enhanced fluorescence and plasmon emission," Analytical Biochemistry, vol. 337, no. 2, pp. 171-194, 2005.

[21] Q. Min, M. J. L. Santos, E. M. Girotto, A. G. Brolo, and R. Gordon, "Localized Raman enhancement from a double-hole nanostructure in a metal film," The Journal of Physical Chemistry C, vol. 112, no. 39, pp. 15098-15101, 2008.

[22] M. Fan, Z. Zhang, J. Hu et al., "Ag decorated sandpaper as flexible SERS substrate for direct swabbing sampling," Materials Letters, vol. 133, pp. 57-59, 2014.

[23] A. L. C. M. D. Silva, M. G. Gutierres, A. Thesing, R. M. Lattuada, and J. Ferreira, "SPR biosensors based on gold and silver nanoparticle multilayer films," Journal of the Brazilian Chemical Society, vol. 25, no. 5, pp. 928-934, 2014. 
[24] J. Wang, D. Xu, and R. Polsky, "Magnetically-induced solidstate electrochemical detection of DNA hybridization," Journal of the American Chemical Society, vol. 124, no. 16, pp. 42084209, 2002.

[25] H. A. Atwater and A. Polman, "Plasmonics for improved photovoltaic devices," Nature Materials, vol. 9, no. 3, pp. 205213, 2010.

[26] D. H. Wang, K. H. Park, J. H. Seo et al., "Enhanced power conversion efficiency in PCDTBT/PC 70 BM bulk heterojunction photovoltaic devices with embedded silver nanoparticle clusters," Advanced Energy Materials, vol. 1, no. 5, pp. 766-770, 2011.

[27] K. Tvingstedt, N.-K. Persson, O. Inganäs, A. Rahachou, and I. V. Zozoulenko, "Surface plasmon increase absorption in polymer photovoltaic cells," Applied Physics Letters, vol. 91, no. 11, Article ID 113514, 2007.

[28] R. G. Sabat, M. J. L. Santos, and P. Rochon, "Surface plasmoninduced band gap in the photocurrent response of organic solar cells," International Journal of Photoenergy, vol. 2010, Article ID 698718, 5 pages, 2010.

[29] X. Chen and S. S. Mao, "Titanium dioxide nanomaterials: synthesis, properties, modifications, and applications," Chemical Reviews, vol. 107, no. 7, pp. 2891-2959, 2007.

[30] B. C. O’Regan, J. R. Durrant, P. M. Sommeling, and N. J. Bakker, "Influence of the $\mathrm{TiCl}_{4}$ treatment on nanocrystalline $\mathrm{TiO}_{2}$ films in dye-sensitized solar cells. 2. Charge density, band edge shifts, and quantification of recombination losses at short circuit," Journal of Physical Chemistry C, vol. 111, no. 37, pp. 14001-14010, 2007.

[31] J. A. Fernandes, P. Migowski, Z. Fabrim et al., " $\mathrm{TiO}_{2}$ nanotubes sensitized with CdSe via RF magnetron sputtering for photoelectrochemical applications under visible light irradiation," Physical Chemistry Chemical Physics, vol. 16, no. 19, pp. 91489153, 2014.

[32] C. Hagglund, M. Zach, and B. Kasemo, "Enhanced charge carrier generation in dye sensitized solar cells by nanoparticle plasmons," Applied Physics Letters, vol. 92, no. 1, Article ID 013113, 2008.

[33] Y. Tian and T. Tatsuma, "Mechanisms and applications of plasmon-induced charge separation at $\mathrm{TiO}_{2}$ films loaded with gold nanoparticles," Journal of the American Chemical Society, vol. 127, no. 20, pp. 7632-7637, 2005.

[34] T. Chien, P. Pavaskar, W. H. Hung, S. Cronin, S. Chiu, and S. Lai, "Study of the plasmon energy transfer processes in dye sensitized solar cells," Journal of Nanomaterials, vol. 2015, Article ID 139243, 6 pages, 2015.

[35] F. J. Beck, A. Polman, and K. R. Catchpole, "Tunable light trapping for solar cells using localized surface plasmons," Journal of Applied Physics, vol. 105, no. 11, Article ID 114310, 7 pages, 2009.

[36] B. Wu, X. Wu, C. Guan et al., "Uncovering loss mechanisms in silver nanoparticle-blended plasmonic organic solar cells," Nature Communications, vol. 4, article no. 2004, 2013.

[37] S. A. Maier and H. A. Atwater, "Plasmonics: localization and guiding of electromagnetic energy in metal/dielectric structures," Journal of Applied Physics, vol. 98, no. 1, Article ID 011101, 2005.

[38] J. Turkevich, P. C. Stevenson, and J. Hillier, "A study of the nucleation and growth processes in the synthesis of colloidal gold," Discussions of the Faraday Society, vol. 11, pp. 55-75, 1951.

[39] C. J. Barbé, F. Arendse, P. Comte et al., "Nanocrystalline titanium oxide electrodes for photovoltaic applications," Journal of the American Ceramic Society, vol. 80, no. 12, pp. 3157-3171, 1997.

[40] S. Ito, T. N. Murakami, P. Comte et al., "Fabrication of thin film dye sensitized solar cells with solar to electric power conversion efficiency over 10\%," Thin Solid Films, vol. 516, no. 14, pp. 46134619, 2008.

[41] E. W. McFarland and J. Tang, "A photovoltaic device structure based on internal electron emission," Nature, vol. 421, no. 6923, pp. 616-618, 2003.

[42] P. K. Jain, K. S. Lee, I. H. El-Sayed, and M. A. El-Sayed, "Calculated absorption and scattering properties of gold nanoparticles of different size, shape, and composition: applications in biological imaging and biomedicine," The Journal of Physical Chemistry B, vol. 110, no. 14, pp. 7238-7248, 2006.

[43] P. Dimon, S. K. Sinha, D. A. Weitz et al., "Structure of aggregated gold colloids," Physical Review Letters, vol. 57, no. 5, pp. 595-598, 1986.

[44] K. S. Mayya, V. Patil, and M. Sastry, "An optical absorption investigation of cross-linking of gold colloidal particles with a small dithiol molecule," Bulletin of the Chemical Society of Japan, vol. 73, no. 8, pp. 1757-1761, 2000.

[45] A. O. Govorov, H. Zhang, H. V. Demir, and Y. K. Gun'Ko, "Photogeneration of hot plasmonic electrons with metal nanocrystals: quantum description and potential applications," Nano Today, vol. 9, no. 1, pp. 85-101, 2014.

[46] M. Fan, M. Thompson, M. L. Andrade, and A. G. Brolo, "Silver nanoparticles on a plastic platform for localized surface plasmon resonance biosensing," Analytical Chemistry, vol. 82, no. 15, pp. 6350-6352, 2010.

[47] F. Eftekhari, C. Escobedo, J. Ferreira et al., "Nanoholes as nanochannels: flow-through plasmonic sensing," Analytical Chemistry, vol. 81, no. 11, pp. 4308-4311, 2009.

[48] P. V. Kamat, "Quantum dot solar cells. Semiconductor nanocrystals as light harvesters," The Journal of Physical Chemistry C, vol. 112, no. 48, pp. 18737-18753, 2008.

[49] M. Haruta, "Size- and support-dependency in the catalysis of gold," Catalysis Today, vol. 36, no. 1, pp. 153-166, 1997.

[50] T. Bora, H. H. Kyaw, S. Sarkar, S. K. Pal, and J. Dutta, "Highly efficient $\mathrm{ZnO} / \mathrm{Au}$ Schottky barrier dye-sensitized solar cells: role of gold nanoparticles on the charge-transfer process," Beilstein Journal of Nanotechnology, vol. 2, no. 1, pp. 681-690, 2011.

[51] J. Qi, X. Dang, P. T. Hammond, and A. M. Belcher, "Highly efficient plasmon-enhanced dye-sensitized solar cells through metal@oxide core-shell nanostructure," ACS Nano, vol. 5, no. 9, pp. 7108-7116, 2011.

[52] M. K. Nazeeruddin, E. Baranoff, and M. Grätzel, "Dyesensitized solar cells: a brief overview," Solar Energy, vol. 85, no. 6, pp. 1172-1178, 2011.

[53] K. G. Deepa, P. Lekha, and S. Sindhu, "Efficiency enhancement in DSSC using metal nanoparticles: a size dependent study," Solar Energy, vol. 86, no. 1, pp. 326-330, 2012.

[54] Y.-H. Su, Y.-F. Ke, S.-L. Cai, and Q.-Y. Yao, "Surface plasmon resonance of layer-by-layer gold nanoparticles induced photoelectric current in environmentally-friendly plasmonsensitized solar cell," Light: Science \& Applications, vol. 1, article e14, 2012.

[55] P. Reineck, G. P. Lee, D. Brick, M. Karg, P. Mulvaney, and U. Bach, "A solid-state plasmonic solar cell via metal nanoparticle self-assembly," Advanced Materials, vol. 24, no. 35, pp. 47504755, 2012. 
[56] Y. Nishijima, K. Ueno, Y. Yokota, K. Murakoshi, and H. Misawa, "Plasmon-assisted photocurrent generation from visible to near-infrared wavelength using a Au-nanorods $/ \mathrm{TiO}_{2}$ electrode," The Journal of Physical Chemistry Letters, vol. 1, no. 13, pp. 2031-2036, 2010.

[57] C. Andrei, E. Lestini, S. Crosbie, C. De Frein, T. O'Reilly, and D. Zerulla, "Plasmonic enhancement of dye sensitized solar cells via a tailored size-distribution of chemically functionalized gold nanoparticles," PLoS ONE, vol. 9, no. 10, Article ID e109836, 2014.

[58] A. Furube, L. Du, K. Hara, R. Katoh, and M. Tachiya, "Ultrafast plasmon-induced electron transfer from gold nanodots into $\mathrm{TiO}_{2}$ nanoparticles," Journal of the American Chemical Society, vol. 129, no. 48, pp. 14852-14853, 2007.

[59] S. Mubeen, G. Hernandez-Sosa, D. Moses, J. Lee, and M. Moskovits, "Plasmonic photosensitization of a wide band gap semiconductor: converting plasmons to charge carriers," Nano Letters, vol. 11, no. 12, pp. 5548-5552, 2011.

[60] Y. H. Jang, Y. J. Jang, S. T. Kochuveedu, M. Byun, Z. Lin, and D. H. Kim, "Plasmonic dye-sensitized solar cells incorporated with $\mathrm{Au}-\mathrm{TiO}_{2}$ nanostructures with tailored configurations," Nanoscale, vol. 6, no. 3, pp. 1823-1832, 2014. 

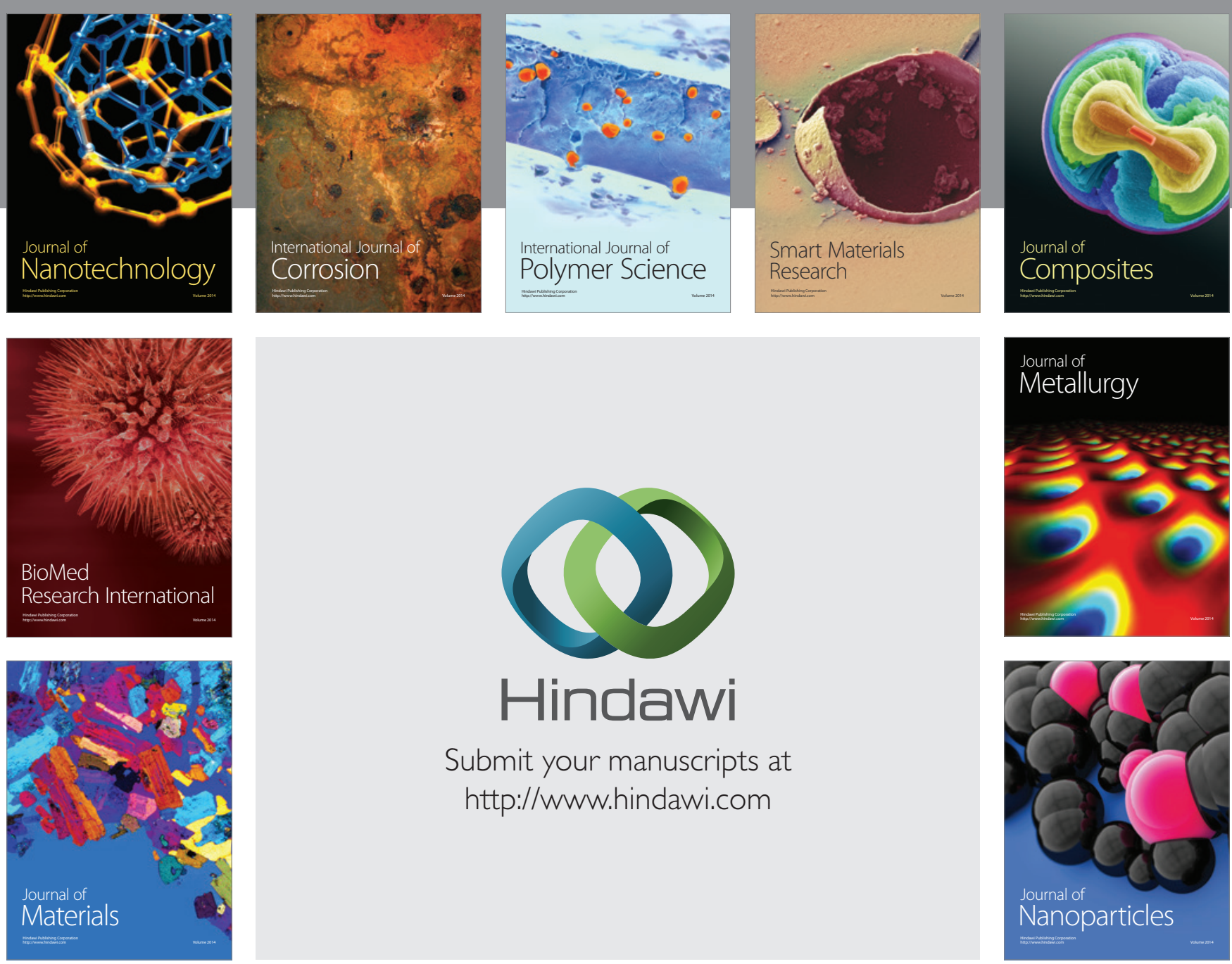

Submit your manuscripts at http://www.hindawi.com
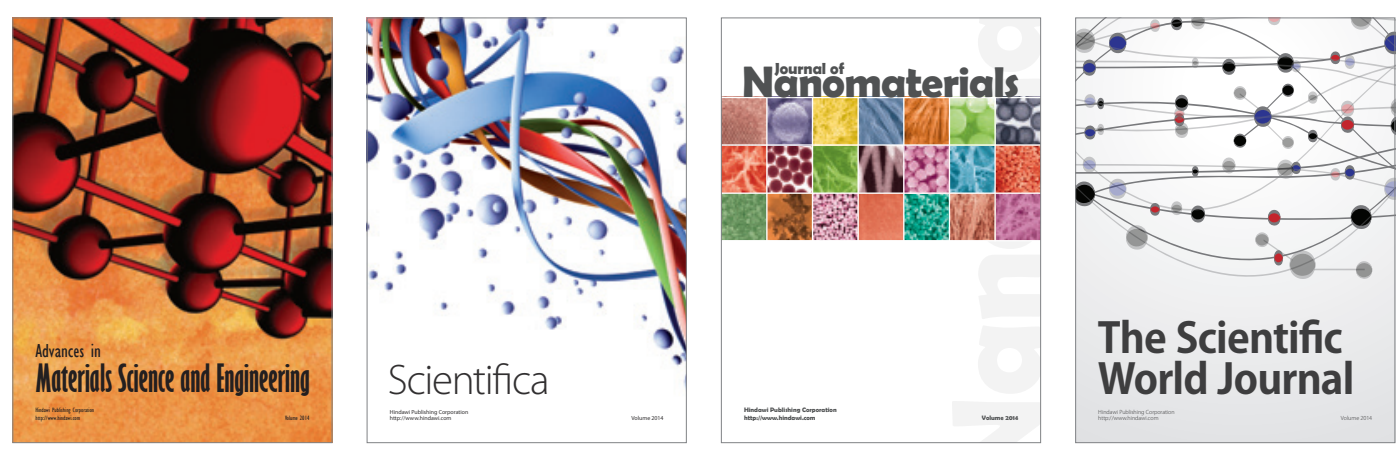

\section{The Scientific World Journal}
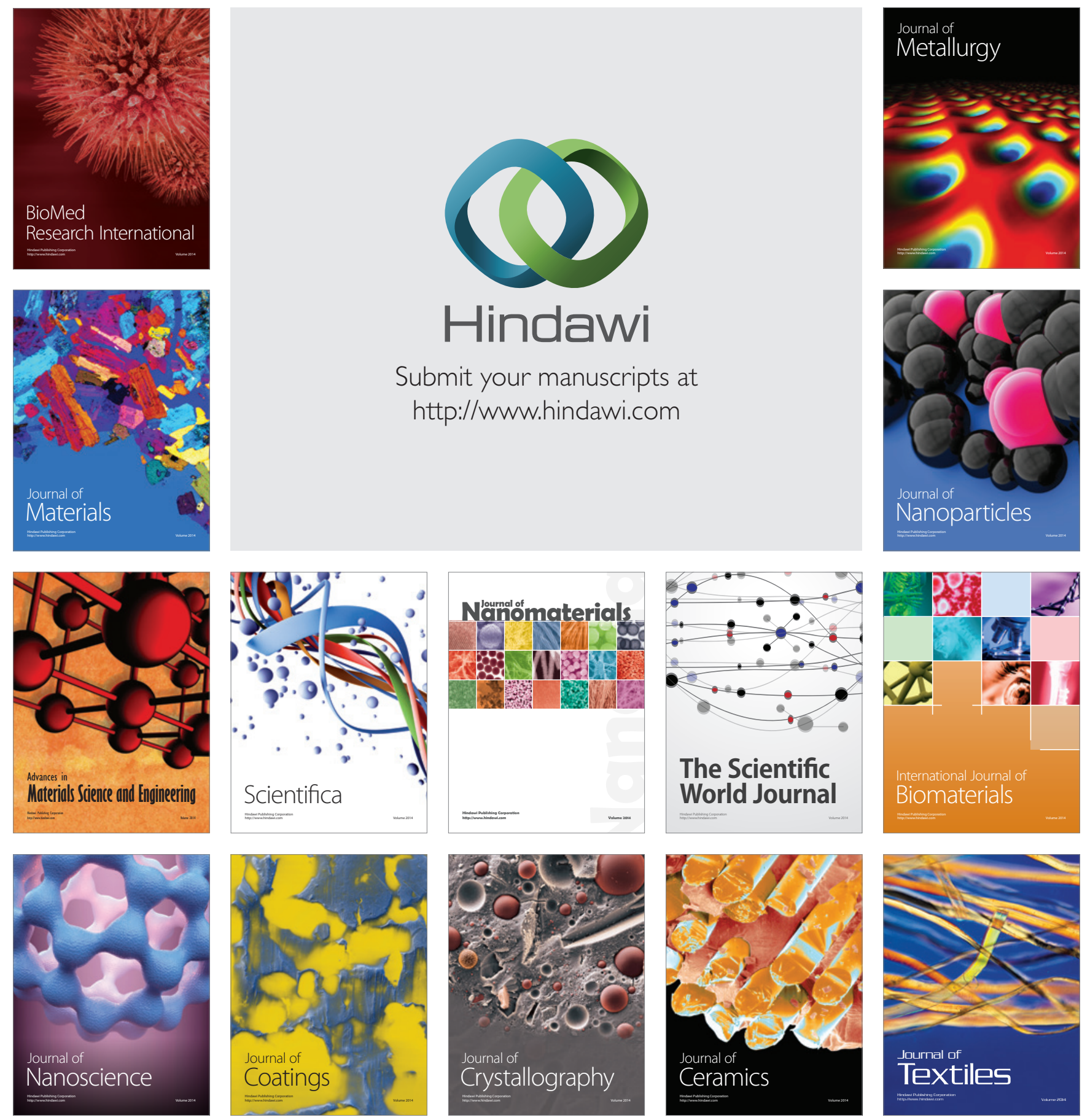